\title{
CFD Simulation of HAWT Blade and Implementation of BEM Theory
}

\author{
Muhammad Faizan Younas ${ }^{1}$, Awais Ali $^{1}$ and Muhammad Daud Shafique ${ }^{1}$
}

\begin{abstract}
:
Wind turbine blade design is of profound importance in the renewable energy industry. This paper reflects a simple yet effective methodology to simulate a Horizontal Axis Wind Turbine (HAWT) blade. A blade of HAWT was designed with the implementation of the Blade Element Momentum Theory (BEM). With a Tip speed ratio (TSR) of 8, a blade of radius $10 \mathrm{~m}$ was designed with NACA 63-615 as a considered airfoil. In order to study the characteristics of flow over the designed blade, Computational Fluid Dynamics (CFD) simulations using ANSYS Fluent package were performed. Using frame motion, an unstructured mesh of around 2 million, and $y+=1$, contours of pressure, velocity, and flow around the immediate vicinity of the blade were shown. The value of torque was found to be $5.6 \mathrm{kN}$.m for the designed blade. Lastly, a grid convergence study was done to find out the optimal size of mesh for this kind of simulation. Results clearly showed the efficacy of fluent package to model simulations of this type.
\end{abstract}

Keywords: Blade Element Momentum Theory, Computational Fluid Dynamics, Tip Speed Ratio, ANSYS Fluent Package

\section{Introduction}

Blade of a HAWT is of great importance for wind turbines. They can have myriad configurations in length, type and number of airfoils. Mostly blades are composed of a number of airfoils, instead of one, in order to ensure maximum lift at each section. BEM theory is a frequently used approach for the design of a HAWT blade. BEM is used by nearly all wind industries for the blade design and its optimization. It is a highly derivative form of Newton's second law of motion[1], and currently the only commercially available source for blade design. BEM theory considers a HAWT blade to be composed of a number of elements. With an input value of TSR, free stream velocity, lift coefficient and design angle of attack (AOA), BEM

${ }^{1}$ Dpeartment of Mechanical Engineering, COMSATS University Islamabad, Sahiwal Campus, Sahiwal, Pakistan

*Corresponding Author: faizanyounas356@gmail.com 
provides important design parameters i.e. twist distribution, chord distribution, and a relative tip speed ratio of every blade element [2-6]. In addition to the design process, by utilizing an iterative process BEM is also useful for the numerical computation of HAWT performance [7, 8].

In today's dynamic engineering environment, CFD is a burgeoning tool and has a broad spectrum of usage in myriad engineering fields. From modeling turbulence[9, 10], various chemical phenomena $[11,12]$, HVAC systems [13, 14] and all the way to the food industry $[15,16]$ CFD has proven potential. The following are some of the studies related to current work.

C. J. Bai et.al. [17] designed a HAWT with the application of BEM theory. Their study considered the National Renewable Energy Research Laboratory's (NREL) airfoil S822, a blade of radius $3 \mathrm{~m}$ and an estimated output of $10 \mathrm{~kW}$. In addition, the improved BEM theory which includes Prandlt's tip-loss correction factor and Viterna-Corrigan stall model was used for performance prediction. In order to bolster the result, ANSYS Fluent package with k- $\omega$ SST turbulence model was used to verify the results obtained from BEM. A good agreement was found between results from BEM and that obtained from CFD simulations.

In a study conducted by Mehmet Bakirci [18], two airfoils i.e. NACA 64-421 and NACA 65-415 were taken under consideration. In order to find the OTSR (Optimum Tip Speed Ratio), six blade geometries were developed using of BEM at tip-speed ratios of 6,7 , and 8 . For the analysis part BEM and CFD were deployed. A grid convergence study was also performed, with $\mathrm{k}-\omega$ SST turbulence model the most accurate results were found at 2 million elements. The results shown a good agreement with BEM analysis, it is worth mentioning that in every case the maximum power coefficient

found at TSR greater than considered in design.
In order to find the starting torque behavior, a small HAWT was designed by Umesh et.al.[19], BEM was used for the design and analysis part. A computer program code with application of MATLAB was generated to predict performance. Moreover, ADAMS software was used in order to verify the results of BEM computationally. With a blade radius of $5 \mathrm{~m}$, consistent values of torque were obtained after $5 \mathrm{sec}$.

In another study conducted by Emrah Kulunk et.al. [20], author designed a $100 \mathrm{KW}$ HAWT with the application of BEM. The chosen airfoil was NREL S809, with $8.5 \mathrm{~m}$ blade and $9.43 \mathrm{~m}$ rotor radius. Moreover, a MATLAB program was also developed to predict the performance parameters like power, thrust, torque and coefficient of performance at wind velocities ranging from 10 to $100 \mathrm{~m} / \mathrm{s}$. Author also expounded on tip-loss correction factor for performance prediction. Results shown a direct relation between the wind velocity and performance parameters, but up to a certain limit this relation is not much dominant, and increasing velocities does not tantamount to performance increase.

A study was conducted to predict the performance of $150 \mathrm{KW}$ HAWT numerically and experimentally by Yan-Ting Lin et.al. [21]. At different pitch angles the performance of HAWT with $10.8 \mathrm{~m}$ blade radius was investigated. Both BEM and CFD were deployed, with $\mathrm{k}-\mathcal{E}$ turbulence model the best results were found at pitch angle $5^{\circ}$. Moreover, results obtained from CFD and BEM shown a good agreement. In a similar approach, effect of pitch angle on HAWT performance was studied by Sudhamshu et.al.[22]. At wind velocities of 7, 15.1, and $25.1 \mathrm{~m} / \mathrm{s}$ ANSYS Fluent package with SST $\mathrm{k}-\omega$ turbulence model was used to find best pitch angle. Results shown inverse relation of thrust coefficient with pitch angle.

Furthermore, for any given velocity optimum pitch angle was also studied.

A number of CFD studies were performed in past to investigate wind turbine performance. Lee et.al.[23] conducted study to investigate 
the effect of blunt airfoil on HAWT performance, with the application of ANSYS Fluent, HAWT blade were tested at different wind speeds. Results proven the blunt airfoil to be auspicious. Especially for small HAWT; mainly because they operate on higher TSR. Four methods for mesh independence study i.e. Grid Convergence Study (GCS), General Richardson Extrapolation (GRE), Mesh Refinement (MR) and Fitting Method (FM) was

investigated by Almohammadi et.al.[24] in case of a Vertical Axis Wind Turbine (VAWT). Results proven the fitting method to be best without any need for large mesh sizes.

A study was conducted by Moshfegi et.al. [25]. Using SST $k-\omega$ turbulence model the effect of near wall grid spacing was studied. Along the chord the separation point was found to be important factor after conducting 8 different cases, with element size no more than 5 million in every case. Similar studies that chronicles around different CFD techniques to study WT performance were describe in[26-34]

\section{Methodoogy}

\subsection{BEM}

For the implementation of BEM. The total length of the blade was divided into " $n$ " number of elements, BEM treats every element as an independent member and provides design characteristics i.e. twist distribution and chord distribution that suits best at that member. In our case, the blade was divided into 10 elements with each of length $1 \mathrm{~m}$. For the BEM implementation, the input parameters are given in Table-1.

Table I: Design parameters

\begin{tabular}{|lc|}
\hline Lift coefficient $\left(\mathrm{C}_{\mathrm{l}}\right)$ & 1.1094 \\
Blade radius $(\mathrm{R})$ & $10 \mathrm{~m}$ \\
No, of blades $\left(\mathrm{N}_{\mathrm{b}}\right)$ & 3 \\
Inlet velocity $\left(\mathrm{V}_{\mathrm{i}}\right)$ & $10 \mathrm{~m} / \mathrm{s}$ \\
Angle of attack $\left(\alpha_{\mathrm{d}}\right)$ & 5.0 \\
Tip speed ratio $(\Lambda)$ & 8 \\
\hline
\end{tabular}

Following steps detail the procedure followed to calculate blade design parameters with BEM theory:

Obtain local tip speed ratio for every element

$$
\Lambda_{\mathrm{r}}=\mathrm{A}\left(\frac{\mathrm{r}}{\mathrm{R}}\right)
$$

where $r$ is the local blade radius ranging from $1-10$

Calculate optimum relative wind angle for every element

$$
\emptyset_{r}=\frac{2}{a}\left(\tan ^{-1} \frac{1}{\Delta r}\right)
$$

Calculation of twist distribution

$$
\theta=\phi_{r}-\alpha_{\mathrm{d}}
$$

Calculation of chord distribution

$$
C_{d y}=\frac{B P_{c_{f} r} \pi \sin \varphi_{r}}{N_{b} C_{l}}
$$

where $\mathrm{P}_{\mathrm{cf}}$ is the Prandlt's tip loss correction factor given by

$$
P_{c f}=\frac{2}{\pi} \cos ^{-1}\left[\exp \left(\frac{\frac{N_{h}}{\frac{2}{T}}\left[\frac{\pi}{R}-1\right)}{\frac{\pi}{R} \sin \phi_{s}}\right)\right]
$$

At every element of the blade calculations were performed using above steps. Table- 2 shows the output design parameters.

Fig. 1 shows the distribution of chord along the blade, as moving along the blade length, chord length decreases, same is the case with twist distribution and optimum relative wind angle shown in fig. 2 and fig. 3. In contrast, 
local TSR increases along the blade length shown in fig. 4

Table II: Calculated design parameters

\begin{tabular}{|c|c|c|c|c|c|}
\hline $\begin{array}{l}\text { Element } \\
\text { Number }\end{array}$ & $\begin{array}{c}\text { Local } \\
\text { Radius } \\
\mathrm{r} \\
(\mathrm{m})\end{array}$ & $\begin{array}{l}\text { Local } \\
\text { TSR } \\
\left(\Lambda_{\mathrm{r}}\right)\end{array}$ & $\begin{array}{c}\text { Twist } \\
\text { Distribution } \\
\left(\theta^{\circ}\right)\end{array}$ & $\begin{array}{c}\text { Chord } \\
\text { Distribution } \\
C_{d r} \\
(\mathrm{~m})\end{array}$ & $\begin{array}{c}\text { Relative } \\
\text { wind } \\
\text { angle } \\
\emptyset_{r} \\
\left(\theta^{\circ}\right)\end{array}$ \\
\hline 1 & 1 & 0.8 & 29.22 & 1.327 & 34.22 \\
\hline 2 & 2 & 1.6 & 16.34 & 1.05 & 21.34 \\
\hline 3 & 3 & 2.4 & 10.08 & 0.791 & 15.08 \\
\hline 4 & 4 & 3.2 & 6.57 & 0.622 & 11.57 \\
\hline 5 & 5 & 4.0 & 4.36 & 0.509 & 9.36 \\
\hline 6 & 6 & 4.8 & 2.85 & 0.429 & 7.85 \\
\hline 7 & 7 & 5.6 & 1.75 & 0.371 & 6.75 \\
\hline 8 & 8 & 6.4 & 0.92 & 0.321 & 5.92 \\
\hline 9 & 9 & 7.2 & 0.27 & 0.261 & 5.27 \\
\hline & 10 & 80 & & & \\
\hline
\end{tabular}

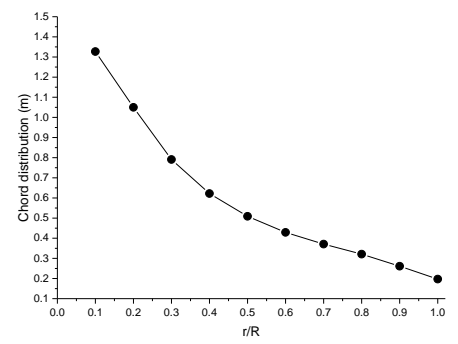

Fig. 1. Variation of chord distribution with blade length

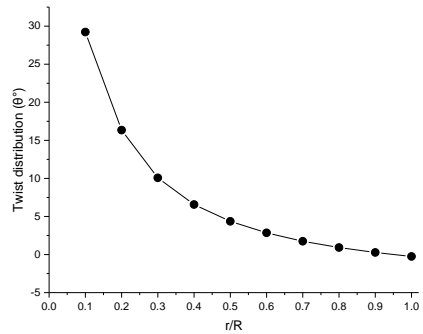

Fig. 2. Variation of twist distribution with blade length

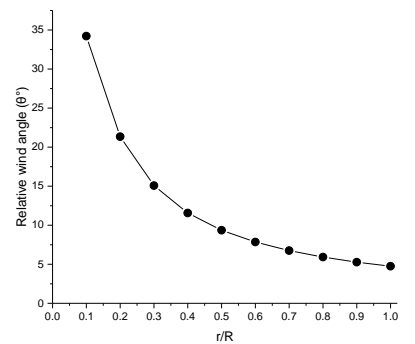

Fig. 3. Variation of relative wind angle with blade length

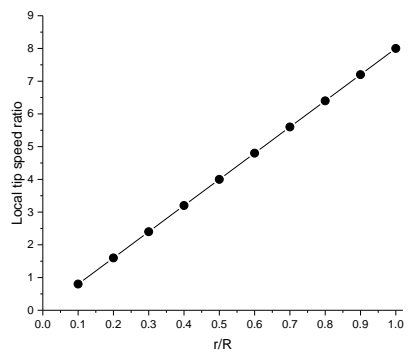

Fig. 4. Variation of local tip speed ratio with blade length

The calculated design parameters were used to create a CAD model in SolidWorks, the modeled blade is shown in fig. 5. It is worth mentioning that a hub radius of $0.5 \mathrm{~m}$ was assumed, but is not modeled in the present study as the only focus was to simulate the rotor.

To bolster the fact that we did not model the hub is because of its aerodynamic shape, which does not hinder the performance of the turbine, hence its effect can be neglected.

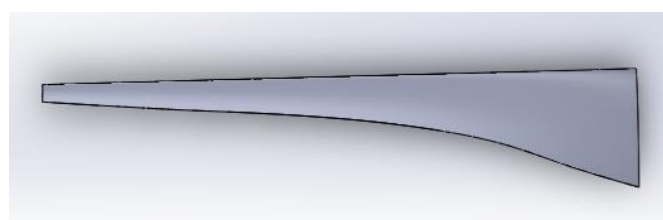

Fig. 5. CAD model of blade

\subsection{CFD Analysis of Airfoil}

Since airfoil $\mathrm{C}_{\mathrm{L}}$ is an input parameter so it is a good reason to perform 2D CFD analysis of the airfoil. 2D simulations were performed on an airfoil at $5^{\circ}$ AOA, which is the maximum $\mathrm{C}_{\mathrm{L}} / \mathrm{C}_{\mathrm{d}}$ angle for this airfoil. A Cshape fluid domain was created with airfoil sitting in between the control volume Fig. 6 . 


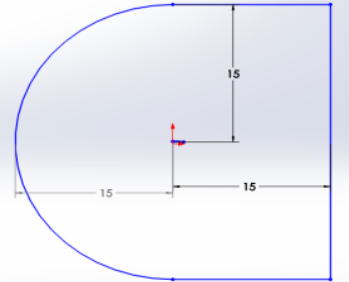

Fig. 6. C-shape control volume

The boundaries of the control volume were extended $15 \mathrm{~m}$ from the airfoil, and the length considered for airfoil was $1 \mathrm{~m}$. A structured mesh was created in the fluid domain after importing geometry in ANSYS Fluent. As shown in Fig. 7, the mesh was refined at the vicinity of the airfoil using a biasing function.

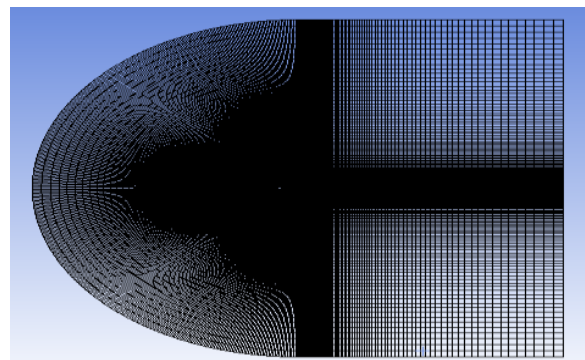

Fig. 7. Structured mesh around airfoil

The size of the mesh in Fig. 7 was around $100 \mathrm{~K}$ elements, as not much of variation in results was encountered upon increasing the size from $100 \mathrm{~K}$.

Fig. 8 shows the structured mesh around the airfoil.

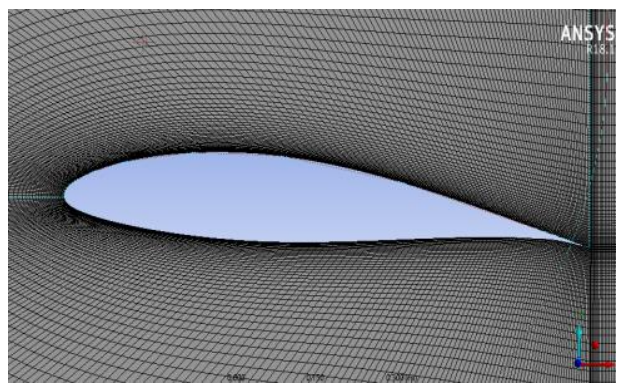

Fig.8. Structured mesh around airfoil
Fig. 9 and fig. 10 shows the mesh around leading and trailing edge of the airfoil.

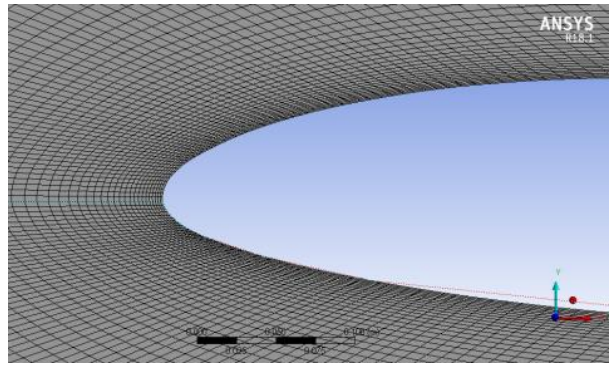

Fig. 9. Mesh around leading edge

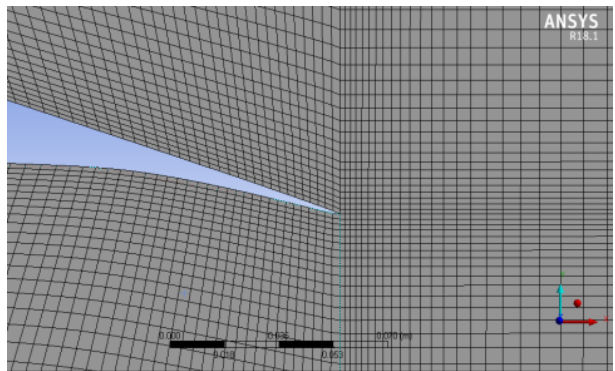

Fig. 10. Mesh around trailing edge

With an inlet velocity of $10 \mathrm{~m} / \mathrm{s}$, the residuals of 1e-6 were set for 2D simulations. Because of the variation of the fluid velocity at the upper and lower side of the airfoil, a pressure difference was developed, and responsible for the lift creation.

Fig. 11 shows the pressure and velocity contours around the airfoil.

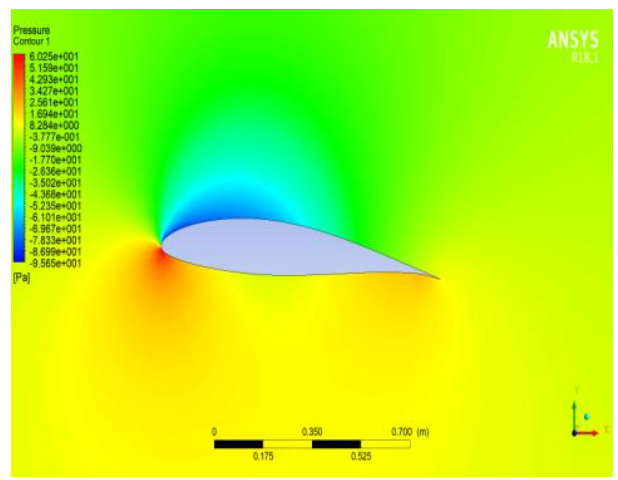

(a) 


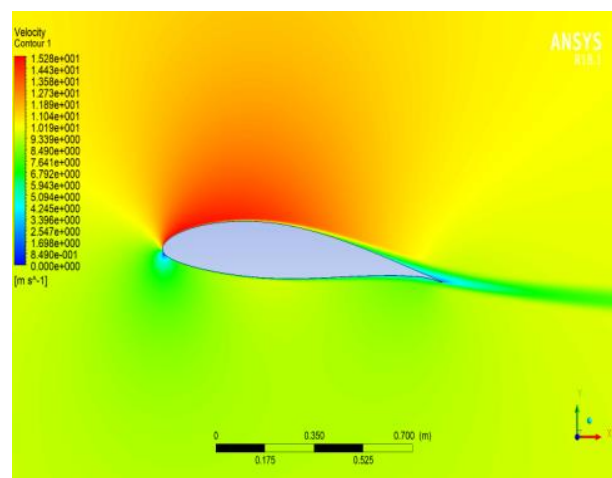

(b)

Fig. 11. (a) pressure contours around airfoil (b) velocity contours around airfoil

\subsection{CFD Analysis of HAWT}

To simulate the rotor a pie-shape domain was created. With the simulation of a single blade, and implementing a symmetry boundary condition, complete rotor was analyzed. This little trick thus saved us time and computational resources. Fig. 12 shows a schematic of our designed control volume. Blade was placed at the center of the domain extended to $3 \mathrm{R}$ of the blade from inlet and outlet section.

Similarly, the inlet radius of fluid domain was $2 R$ and $4 R$ for the outlet. Fig. 13 and fig. 14 shows the actual mesh of control volume.

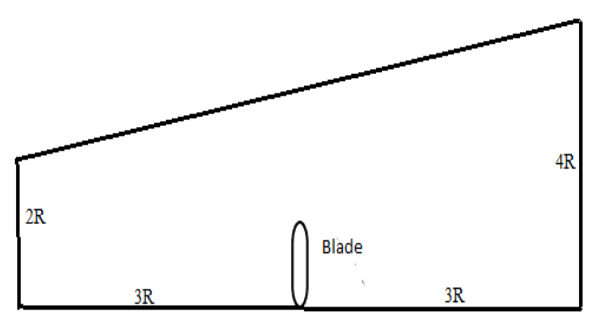

Fig. 12. Schematic of control volume

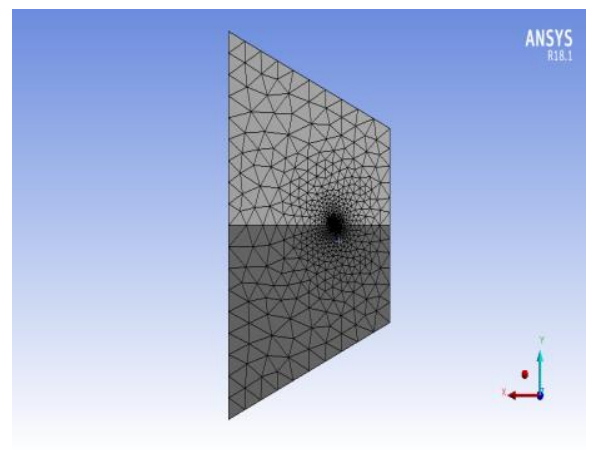

Fig. 13 Mesh of control volume

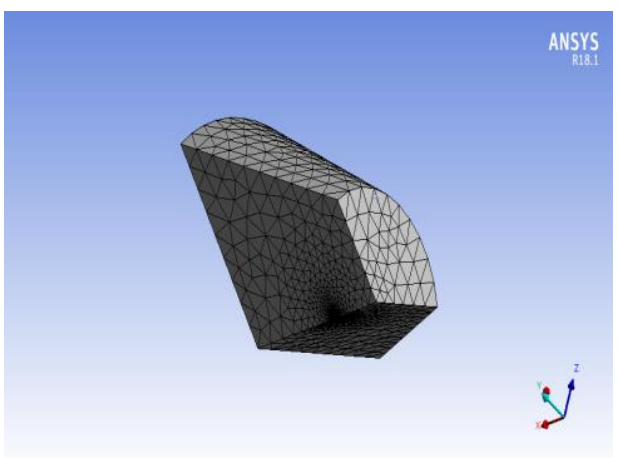

Fig. 14 Mesh of control volume

An unstructured mesh with around 2 million elements was generated. In order to better capture the near wall viscous effects and shear forces a dimensionless wall quantity $y$ + is used. $y+$ is distance of the first computing node from wall. $\mathrm{y}+$ value varies with different turbulence

models, as for $\mathrm{k} \omega$-SST model it is generally, advice to keep y $+<=1$. $\mathrm{k} \omega$-SST is a twoequation eddy viscosity model and is highly effective in aerodynamics applications. It combines the benefits of both k-omega and kepsilon turbulence models, hence well suited for flows in sub viscous layers and regions away from the wall [35].

Moreover, 27 layers of inflation were also part of the mesh, in order to better capture the viscous effects and shear forces near the wall. It may appear as a structured mesh around the airfoil, but these were the inflation layers 
that wrap around the body to capture near wall effects. The mesh for this simulation contains tetrahedral elements only. A cut plane section of blade mesh is shown in fig. 15. and airfoil mesh is shown in fig. 16 .

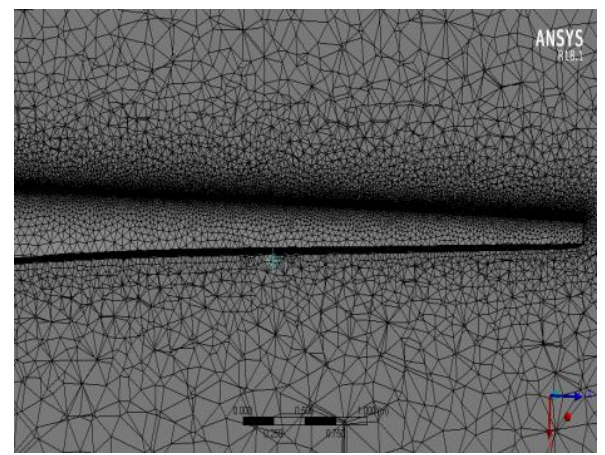

Fig. 15. Mesh around blade

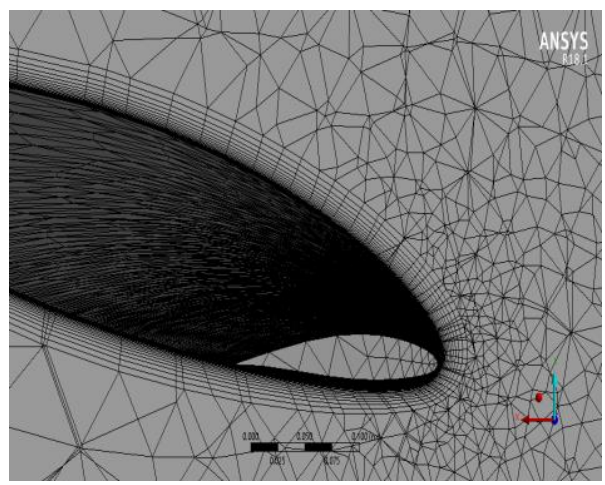

Fig. 16. Mesh around airfoil

Table-3 shows the boundary conditions considered for simulations.

As for the governing equations, Reynoldsaveraged Naiver-stokes (RANS) equation was used to simulate the mean fluid flow given by

$$
\begin{aligned}
& \frac{\partial \nabla_{i}}{\partial t}+\widetilde{D}_{J} \frac{\partial \nabla_{i}}{\partial x_{j}}=
\end{aligned}
$$

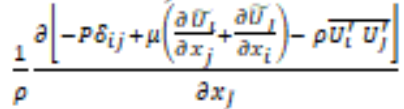

Where $\mathrm{P}$ stands for pressure, the term $\mu\left(\frac{\partial \widetilde{V}_{i}}{\partial x_{j}}+\frac{\partial{\widetilde{V_{j}}}_{j}}{\partial x_{i}}\right)$ are viscous stresses, $\theta$ is the averaged velocity, $\rho$ is density, and $\rho \overline{U_{\mathbb{1}}^{s} U_{j}^{p}}$ are the Reynold stresses. For modeling turbulence, turbulence model komega SST was used. The two-equation model is given by

Table III: Boundary conditions

\begin{tabular}{|c|c|}
\hline Boundary condition & Selection \\
\hline Solver & $\begin{array}{l}\text { Pressure based } \\
\text { Absolute velocity formulation } \\
\text { Steady state simulation }\end{array}$ \\
\hline Fluid material & Air \\
\hline Viscosity & $1.7894 \mathrm{e}-05$ \\
\hline Density & 1.225 \\
\hline Temperature & $300 \mathrm{k}$ \\
\hline Pressure & $101,325 \mathrm{~Pa}$ \\
\hline Wind speed & $10 \mathrm{~m} / \mathrm{s}$ \\
\hline CFD algorithm & Simple \\
\hline Turbulence model & SST-ko \\
\hline Cell zone condition & Frame motion of $2.3 \mathrm{rad} / \mathrm{s}$ \\
\hline Wall condition & Moving wall \\
\hline Solution methods & $\begin{array}{l}\text { No-slip shear condition } \\
\text { SIMPLE Scheme }\end{array}$ \\
\hline & $\begin{array}{l}\text { Gradient: Least square cell based } \\
\text { Pressure: Standard } \\
\text { Momentum: Second order up-wind } \\
\text { Turbulent kinetic energy: First order } \\
\text { up-wind } \\
\text { Specific dissipation rate: First order } \\
\text { up-wind }\end{array}$ \\
\hline Solution controls & $\begin{array}{l}\text { Pressure } 0.3 \\
\text { Density } 1 \\
\text { Momentum } 0.7 \\
\text { Turbulent kinetic energy } 0.8 \\
\text { Specific dissipation rate } 0.8 \\
\text { Turbulent viscosity } 1\end{array}$ \\
\hline Mesh gize & About 2000,000 \\
\hline
\end{tabular}

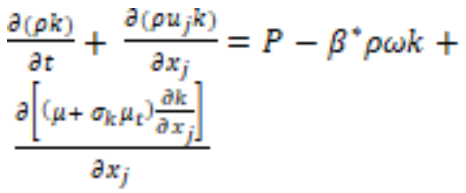

$$
\begin{aligned}
& \frac{\partial(\rho \omega)}{\partial t}+\frac{\partial\left(\rho \mu_{j} \omega\right)}{\partial x_{j}}=\frac{Y}{V_{L}} P-\beta \rho \omega^{2}+ \\
& \frac{\partial\left[\left(\mu+\sigma_{\omega} \mu_{L}\right) \frac{\partial \omega}{\partial x_{j}}\right]}{\partial x}+2\left(1-F_{1}\right) \frac{\rho \sigma_{\omega L}}{\omega} \frac{\partial k}{\partial x_{j}} \frac{\partial \omega}{\partial x_{j}}
\end{aligned}
$$

Furthermore, continuity equation is given by 
$\frac{\partial \rho}{\partial t}+\frac{\partial(\rho u)}{\partial x}+\frac{\partial(\rho v)}{\partial y}+\frac{\partial(\rho w)}{\partial z}=0$

\section{Results and Discussions}

Fig. 17 shows the complete fluid domain. For our simulations, residuals were set to $1 \mathrm{e}$ 6 , and the relaxation factors were set to default. Fig. 18 shows the residuals monitor for our simulation. 1500 iterations were done so ensure the maximum convergence, but it can be seen from residual plots that all the factors approached maximum convergence within 300 iterations, and solution didn't converge much afterwards. The tangential velocity was calculated by $\nu=\omega r$, as $\omega=2.3 \mathrm{rad} / \mathrm{s}$ is selected, the tangential velocity should be $23 \mathrm{~m} / \mathrm{s}$ at the blade tip. Fig. 19 shows the velocity vectors on the simulated rotor, with a maximum velocity of $23 \mathrm{~m} / \mathrm{s}$ at the tip. This is an important step in order to verify that our model worked well.

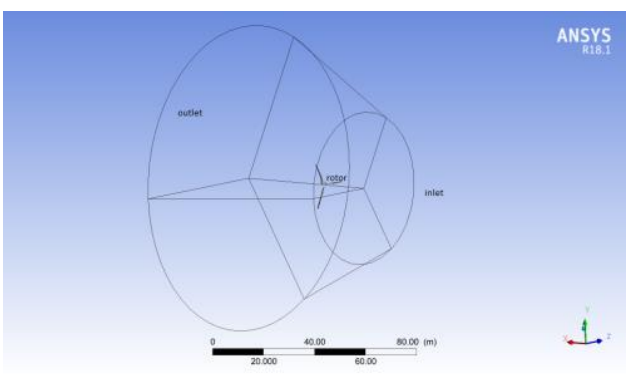

Fig. 17. Complete fluid domain

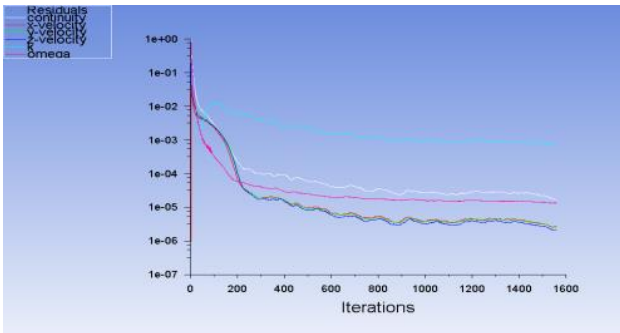

Fig. 18. Scaled residuals

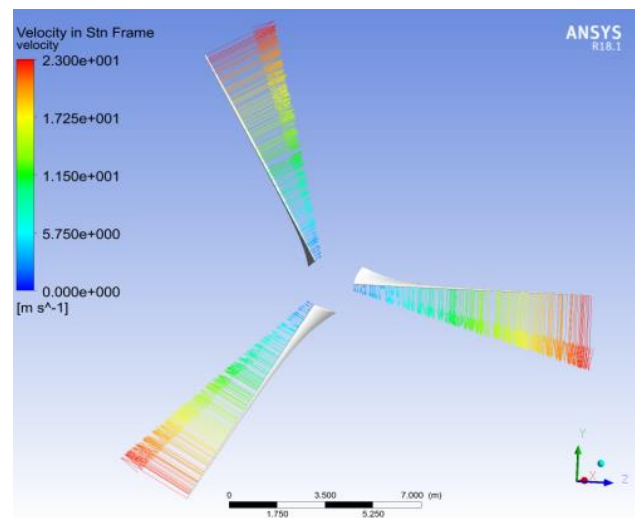

Fig. 19. Velocity vectors in Stn frame

Fig. 20 show the distribution of pressure contours along the blade length, the difference of pressure between both sides of the blade yields axial forces that turns the turbine. This axial force is directly related to the developed pressure difference.

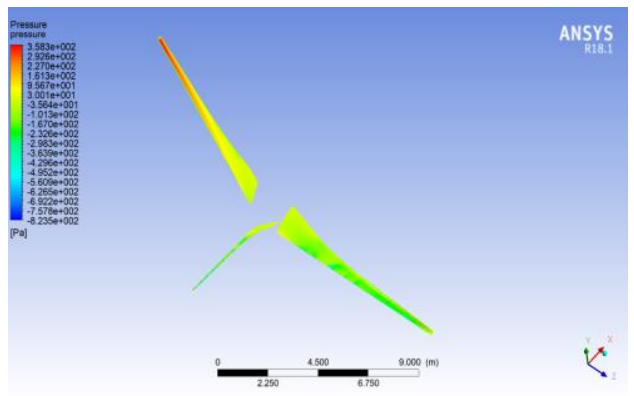

Fig. 20. Pressure contours on rotor

From fig. 21 - fig. 30. pressure contours at each blade element of blade are shown. It can be well observed that as moving along the blade pressure difference increases and every element contributes more to the rotation of the blade.

Minimum pressure was found $18.21 \mathrm{~Pa}$ at first element $(\mathrm{r} / \mathrm{R}=0.1)$ and a maximum of $351 \mathrm{~Pa}$ at the last element $(r / R=1)$ shown in fig. 31 . 


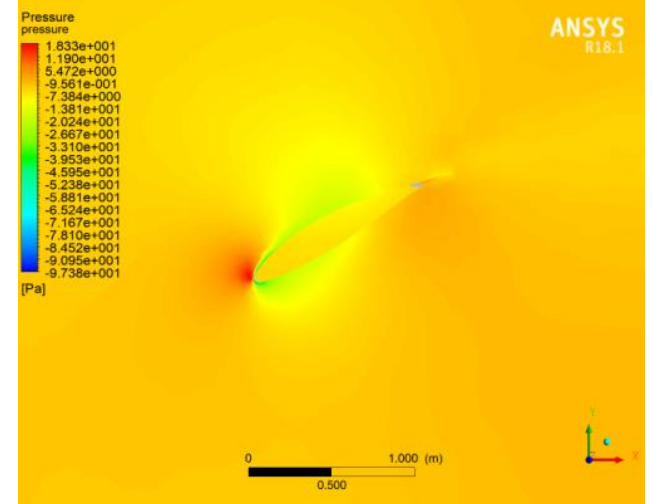

Fig. 21. Pressure contour at $r / R=0.1$

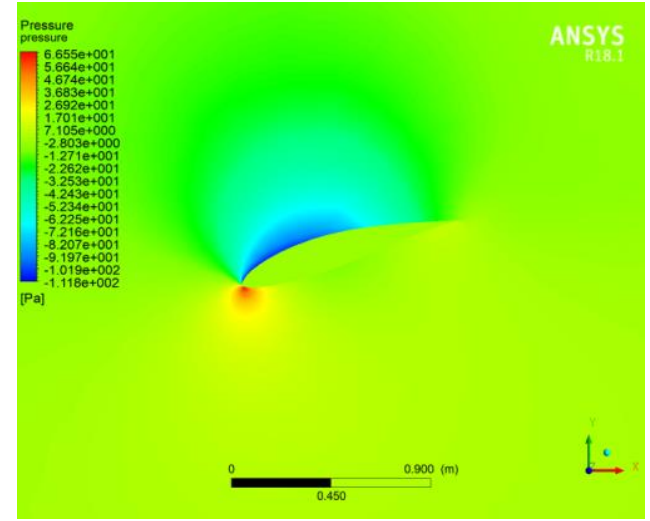

Fig. 22. Pressure contour at $r / R=0.2$

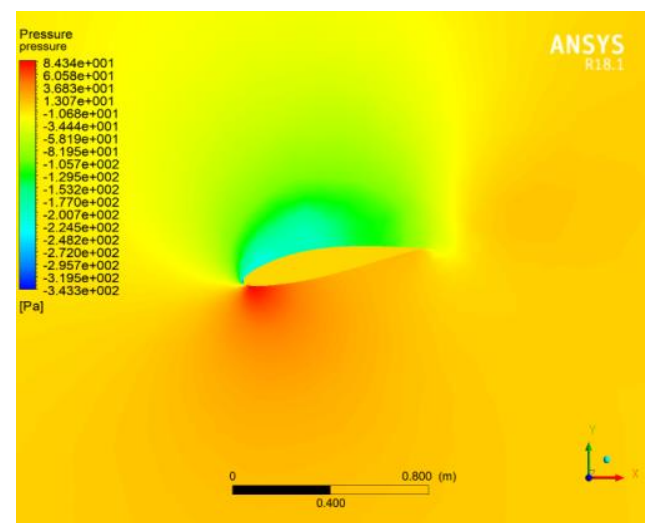

Fig. 23. Pressure contour at $r / R=0.3$

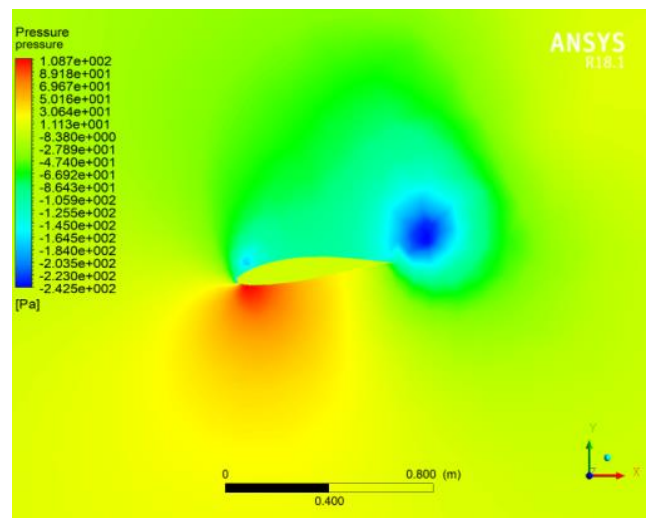

Fig. 24. Pressure contour at $r / R=0.4$

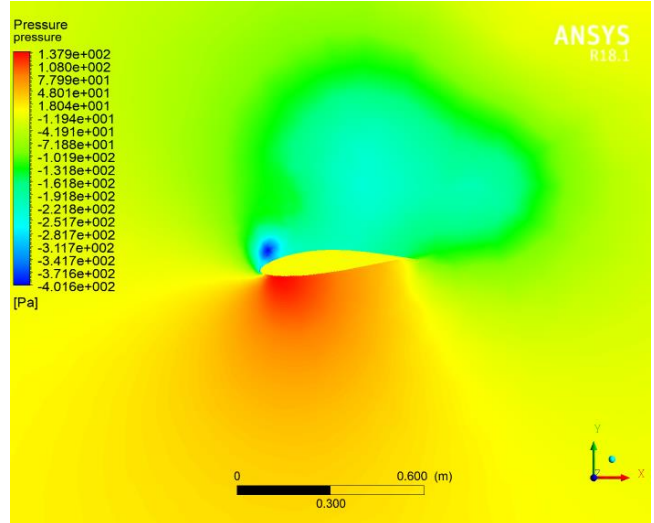

Fig. 25. Pressure contour at $r / R=0.5$

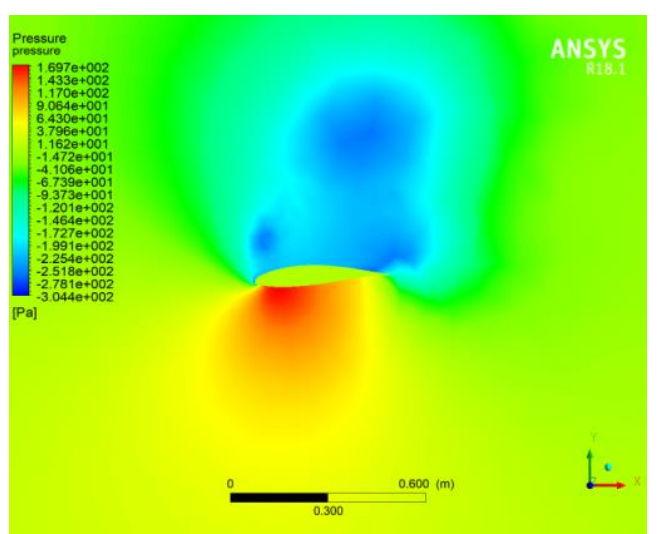

Fig. 26. Pressure contour at $\mathrm{r} / \mathrm{R}=0.6$ 


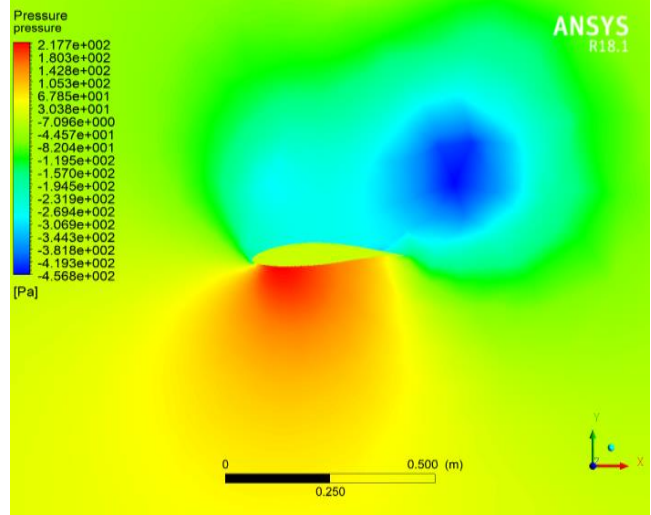

Fig. 27. Pressure contour at $\mathrm{r} / \mathrm{R}=0.7$

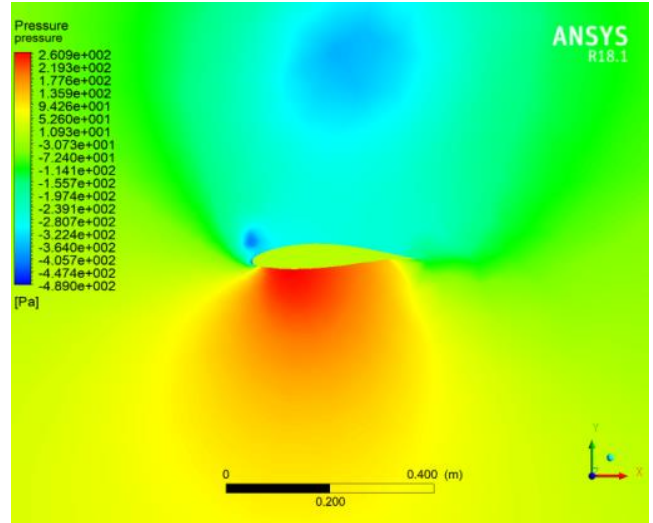

Fig. 28. Pressure contour at $\mathrm{r} / \mathrm{R}=0.8$

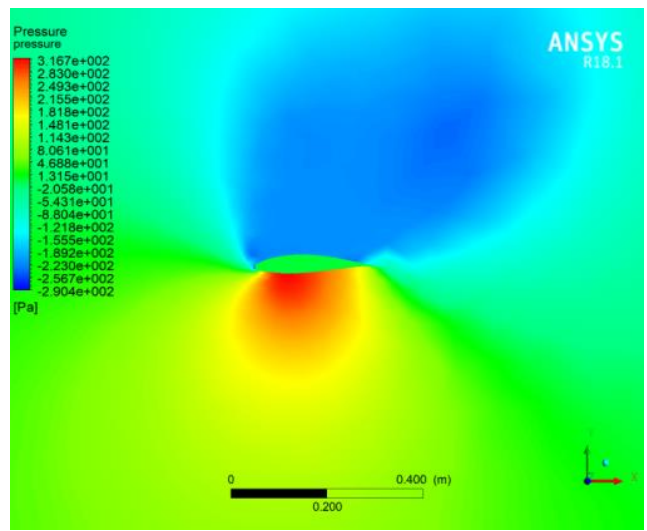

Fig. 29. Pressure contour at $\mathrm{r} / \mathrm{R}=0.9$

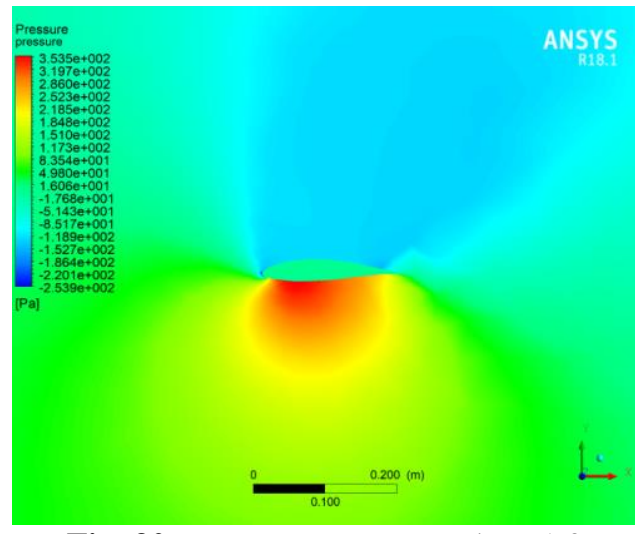

Fig. 30. Pressure contour at $\mathrm{r} / \mathrm{R}=1.0$

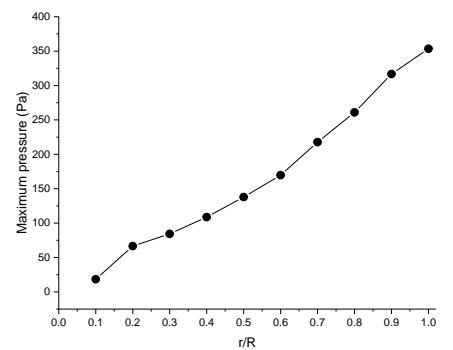

Fig. 31. Pressure distribution along blade

Similarly, from fig. 32 - fig. 41 velocity contours at each section of blade are shown. Like pressure, velocity contours become more aggressive as moving along the blade, with a minimum velocity of $15 \mathrm{~m} / \mathrm{s}$ at first element and maximum of $31 \mathrm{~m} / \mathrm{s}$ at tip section.

This rising trend is because of the decreasing angle of attack and chord distribution along the blade length. 


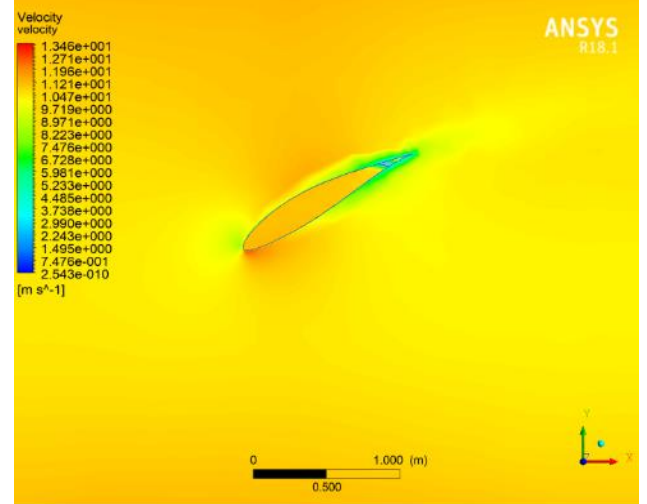

Fig. 32. Velocity contour at $r / R=0.1$

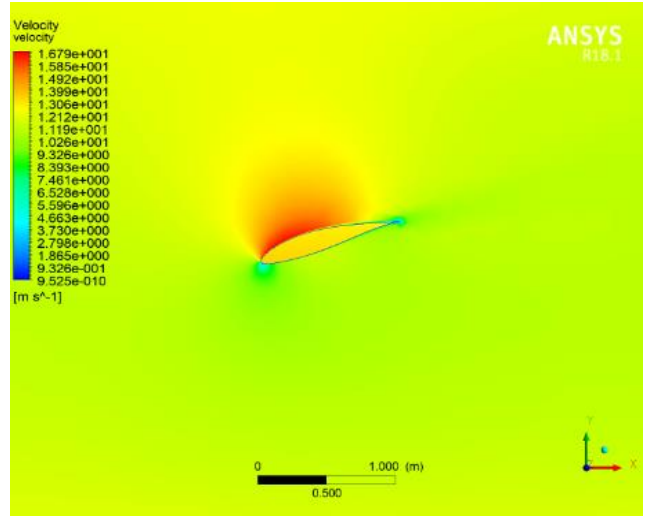

Fig. 33. Velocity contour at $r / R=0.2$

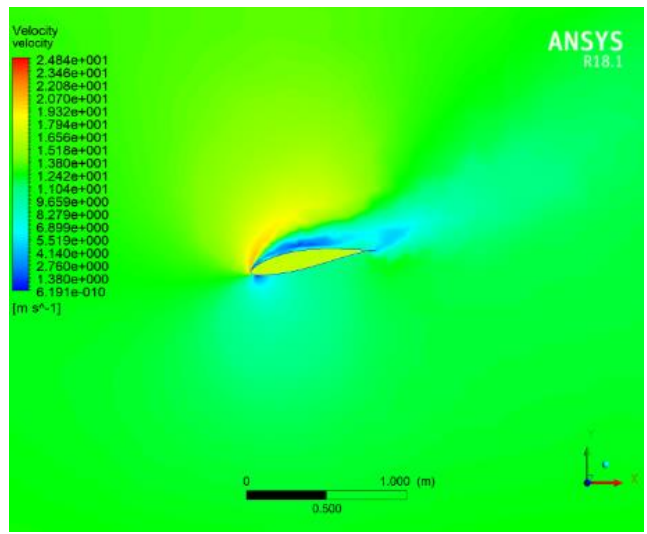

Fig. 34. Velocity contour at $r / R=0.3$

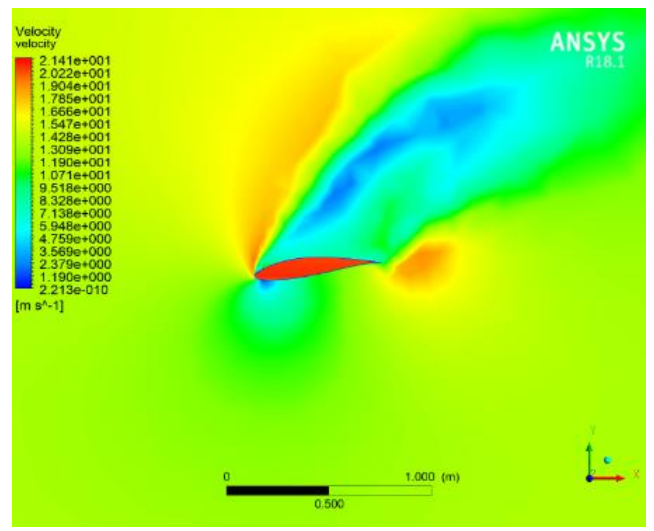

Fig. 35. Velocity contour at $r / R=0.4$

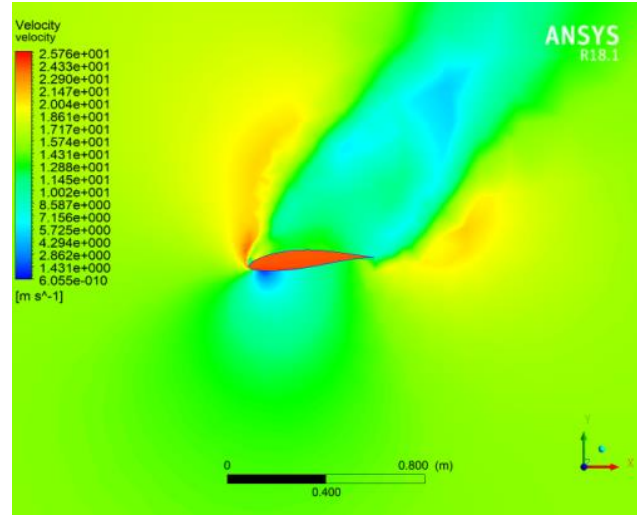

Fig. 36. Velocity contour at $r / R=0.5$

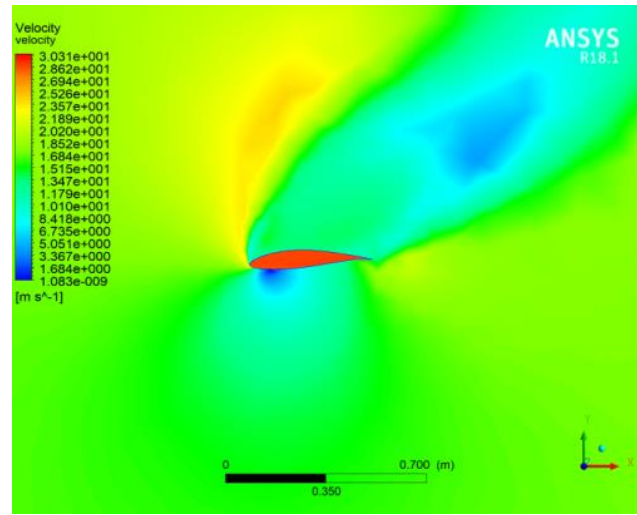

Fig. 37. Velocity contour at $r / R=0.6$ 


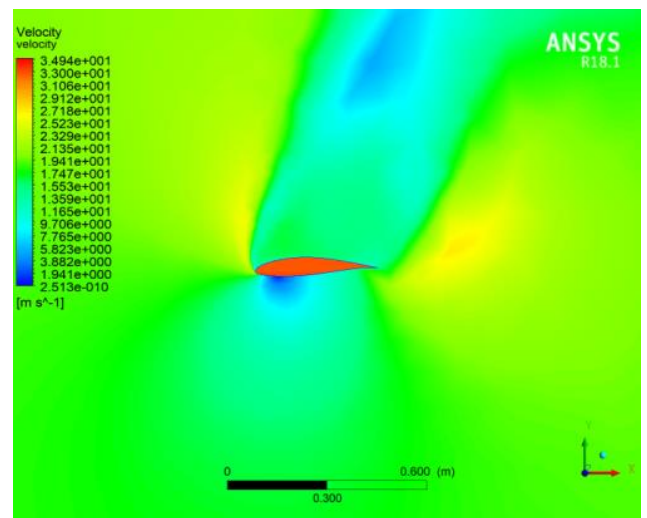

Fig. 38. Velocity contour at $r / R=0.7$

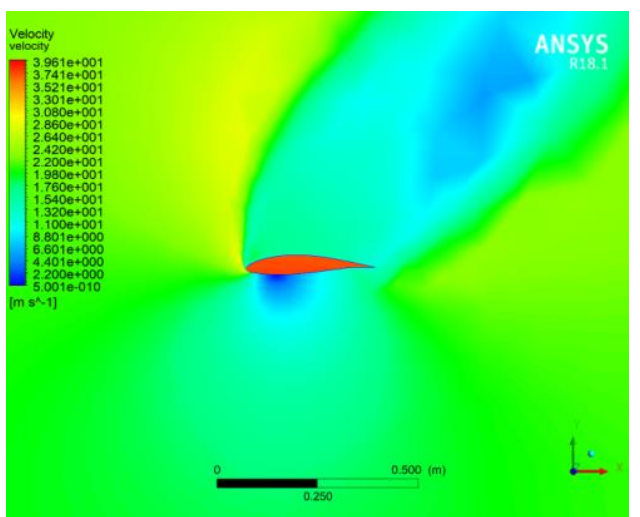

Fig. 39. Velocity contour at $\mathrm{r} / \mathrm{R}=0.8$

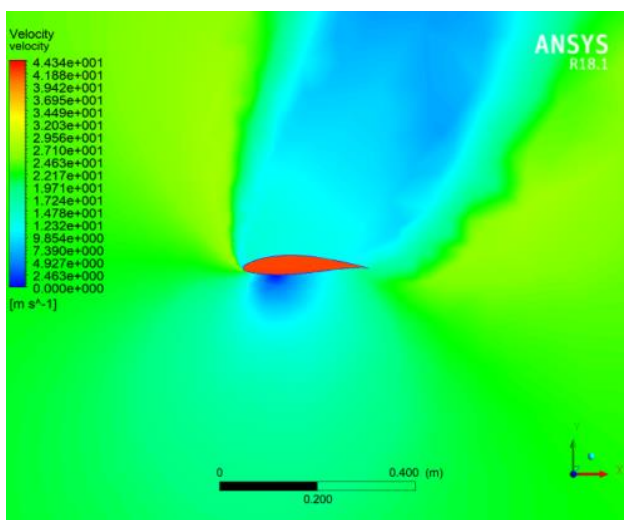

Fig. 40. Velocity contour at $r / R=0.9$

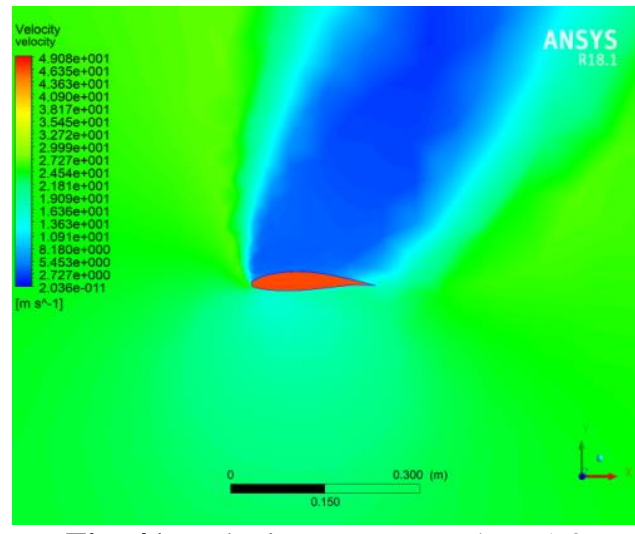

Fig. 41. Velocity contour at $\mathrm{r} / \mathrm{R}=1.0$

Velocity contour at tip section $(\mathrm{r} / \mathrm{R}=1)$ shows the tip losses occurring at the blade. The torque value was also an important factor, at about 2 million mesh size the torque obtained was $5.6 \mathrm{kN} . \mathrm{m}$.

A grid convergence study was done using the MR technique to find the optimum size of mesh for this simulation setup. The variation of torque with mesh size is shown in fig. 42 . As not a clear nuance was found in torque value on increasing mesh from 2 million cells.

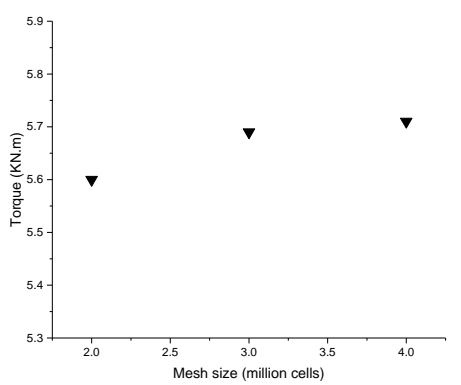

Fig. 42. Torque variation with mesh size

Due to the rotation of wind turbines, a disturbance in medium developed at the exit of the rotor known as wake effect. During the installation of wind farms, this phenomenon should take into consideration, so that the wake of one turbine does not hinder other's performance. 
Fig. 43 shows the effect of the wake behind the moving turbine; the wake is maximum at the immediate exit from the turbine and a decline is observe as moving away from the rotor.
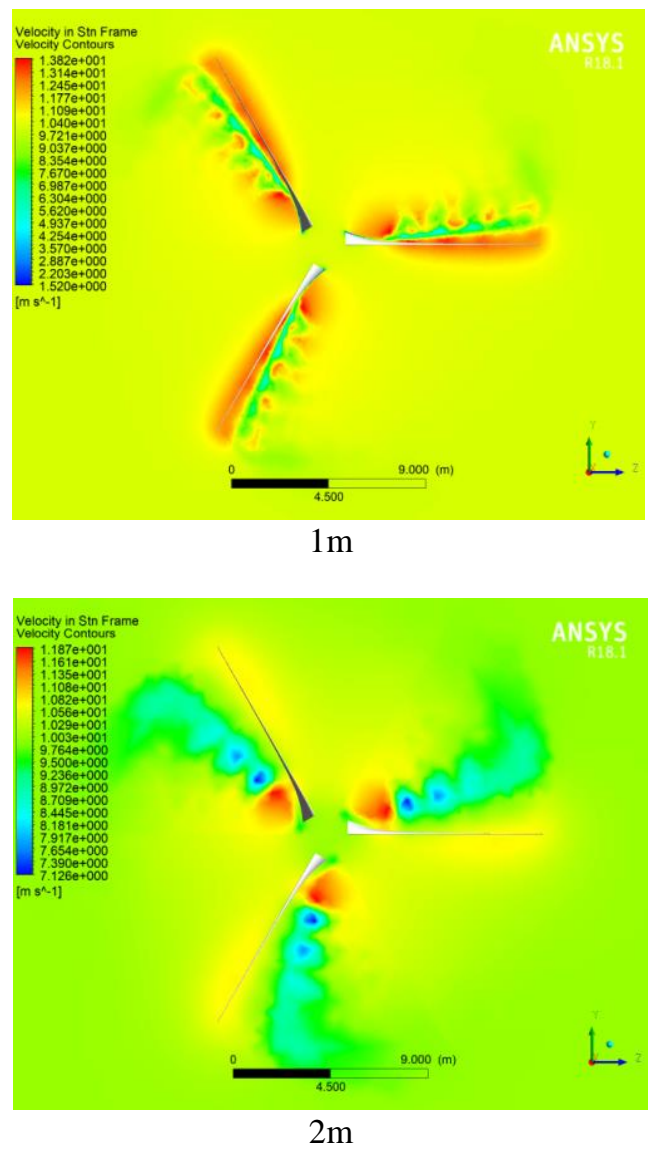

Fig. 43. Wake behind turbine at $1 \mathrm{~m}$ and $2 \mathrm{~m}$

\section{Conclusion and Future Work}

A simple yet effective methodology was proposed to simulate the HAWT blade. Moreover, a mesh refinement study using the MR technique was done to bolster the results. As for future work, this methodology can be implemented on blades with somewhat complex geometries, and a comparison can be done to investigate how far the unstructured mesh holds to provide accurate results. Furthermore, a juxtaposition of results can be done using different techniques of mesh independence study.

\section{Nomenclature}

$\mathrm{C}_{1} \quad$ Lift coefficient

AOA Angle of attack

CFD Computational Fluid Dynamics

FM Fitting Method

WT Wind turbine

GRE General Richardson extrapolation

MR Mesh refinement

GCS Grid convergence study

VAWT Vertical axis wind turbine

$\mathrm{R} \quad$ Blade radius

RANS Reynolds-averaged Naiver-stokes

$\mathrm{N}_{\mathrm{b}} \quad$ Number of blades

$\mathrm{V}_{\mathrm{i}} \quad$ Inlet velocity

$\alpha_{d} \quad$ Design angle of attack

$\Lambda \quad$ Tip speed ratio

$\Lambda_{\mathrm{r}} \quad$ Local tip speed ratio

Optimum wind angle

$D_{y} \quad$ Local optimum wind angle

$\theta \quad$ Twist distribution

$C_{d y} \quad$ Chord distribution

$P_{\text {cf }} \quad$ Prandlt's correction factor

$\omega$ Rotational velocity

HAWT Horizontal axis wind turbine

BEM Blade element momentum theory

2D Two dimension

3D Three dimension

TSR Tip-speed ratio

OTSR Optimum tip-speed ratio

\section{REFERENCES}

[1] M. O. Hansen, Aerodynamics of wind turbines: Routledge, 2015.

[2] F. Bohorquez, D. Pines, and P. D. Samuel, "Small rotor design optimization using blade element momentum theory and hover tests," Journal of aircraft, vol. 47, pp. 268-283, 2010.

[3] E. Kulunk and N. Yilmaz, "Hawt rotor design and performance analysis," in ASME 2009 3rd International Conference on Energy Sustainability collocated with the Heat 
Transfer and InterPACK09 Conferences, 2009, pp. 1019-1029.

[4] E. Kulunk and N. Yilmaz, "Aerodynamic Design and Performance Analysis of HAWT Blades," in ASME 2009 Fluids Engineering Division Summer Meeting, 2009, pp. 12111222.

[5] R. Lanzafame, S. Mauro, and M. Messina, "HAWT design and performance evaluation: improving the BEM theory mathematical models," Energy Procedia, vol. 82, pp. 172179, 2015.

[6] H. A. Madsen, C. Bak, M. Døssing, R. Mikkelsen, and S. Øye, "Validation and modification of the blade element momentum theory based on comparisons with actuator disc simulations," Wind Energy: An International Journal for Progress and Applications in Wind Power Conversion Technology, vol. 13, pp. 373-389, 2010.

[7] W. Duan and F. Zhao, "Loading analysis and strength calculation of wind turbine blade based on blade element momentum theory and finite element method," in 2010 AsiaPacific Power and Energy Engineering Conference, 2010, pp. 1-4.

[8] G. Ingram, "Wind turbine blade analysis using the blade element momentum method. version 1.1," School of Engineering, Durham University, UK, 2005

[9] J. Aubin, D. F. Fletcher, and C. Xuereb, "Modeling turbulent flow in stirred tanks with CFD: the influence of the modeling approach, turbulence model and numerical scheme," Experimental thermal and fluid science, vol. 28, pp. 431-445, 2004

[10] Z. J. Zhai, Z. Zhang, W. Zhang, and Q. Y. Chen, "Evaluation of various turbulence models in predicting airflow and turbulence in enclosed environments by CFD: Part 1Summary of prevalent turbulence models," Hvac\&R Research, vol. 13, pp. 853-870, 2007.

[11] C. Yin, L. A. Rosendahl, and S. K. Kær, "Chemistry and radiation in oxy-fuel combustion: a computational fluid dynamics modeling study," Fuel, vol. 90, pp. 25192529, 2011.

[12] M. N. Kashid, D. W. Agar, and S. Turek, "CFD modelling of mass transfer with and without chemical reaction in the liquid-liquid slug flow microreactor," Chemical Engineering Science, vol. 62, pp. 5102-5109, 2007.

[13] J. Floyd, "Coupling a network HVAC model to a computational fluid dynamics model using large eddy simulation," Fire Safety Science, vol. 10, pp. 459-470, 2011.
[14] A. Patidar, S. Natarajan, and M. Pande, "CFD Analysis and Validation of an Automotive HVAC System," SAE Technical Paper 0148$7191,2009$.

[15] T. Norton and D.-W. Sun, "Computational fluid dynamics (CFD)-an effective and efficient design and analysis tool for the food industry: a review," Trends in Food Science \& Technology, vol. 17, pp. 600-620, 2006.

[16] V. Chanteloup and P.-S. Mirade, "Computational fluid dynamics (CFD) modelling of local mean age of air distribution in forced-ventilation food plants," Journal of Food Engineering, vol. 90, pp. 90-103, 2009.

[17] C. Bai, F. Hsiao, M. Li, G. Huang, and Y. Chen, "Design of $10 \mathrm{~kW}$ horizontal-axis wind turbine (HAWT) blade and aerodynamic investigation using numerical simulation," Procedia Engineering, vol. 67, pp. 279-287, 2013.

[18] M. Bakırci and S. Yilmaz, "Theoretical and computational investigations of the optimal tip-speed ratio of horizontal-axis wind turbines," Engineering Science and Technology, an International Journal, vol. 21, pp. 1128-1142, 2018.

[19] U. Chaudhary, P. Mondal, P. Tripathy, S. K. Nayak, and U. K. Saha, "Modeling and optimal design of small HAWT blades for analyzing the starting torque behavior," in 2014 Eighteenth National Power Systems Conference (NPSC), 2014, pp. 1-6.

[20] E. Kulunk and N. Yilmaz, "HAWT Rotor Design and Performance Analysis," pp. 10191029, 2009.

[21] Y.-T. Lin, P.-H. Chiu, and C.-C. Huang, "An experimental and numerical investigation on the power performance of $150 \mathrm{~kW}$ horizontal axis wind turbine," Renewable Energy, vol. 113, pp. 85-93, 2017/12/01/ 2017.

[22] S. A.R, M. C. Pandey, N. Sunil, S. N.S, V. Mugundhan, and R. K. Velamati, "Numerical study of effect of pitch angle on performance characteristics of a HAWT," Engineering Science and Technology, an International Journal, vol. 19, pp. 632-641, 2016/03/01/ 2016.

[23] S. G. Lee, S. J. Park, K. S. Lee, and C. Chung, "Performance prediction of NREL (National Renewable Energy Laboratory) Phase VI blade adopting blunt trailing edge airfoil," Energy, vol. 47, pp. 47-61, 2012/11/01/ 2012.

[24] K. M. Almohammadi, D. B. Ingham, L. Ma, and M. Pourkashan, "Computational fluid dynamics (CFD) mesh independency techniques for a straight blade vertical axis 
wind turbine," Energy, vol. 58, pp. 483-493, 2013/09/01/2013.

[25] M. Moshfeghi, Y. J. Song, and Y. H. Xie, "Effects of near-wall grid spacing on SST-K$\omega$ model using NREL Phase VI horizontal axis wind turbine," Journal of Wind Engineering and Industrial Aerodynamics, vol. 107-108, pp. 94-105, 2012/08/01/ 2012.

[26] J. M. O'Brien, T. M. Young, J. M. Early, and P. C. Griffin, "An assessment of commercial CFD turbulence models for near wake HAWT modelling," Journal of Wind Engineering and Industrial Aerodynamics, vol. 176, pp. 32-53, 2018/05/01/ 2018.

[27] C.-J. Bai and W.-C. Wang, "Review of computational and experimental approaches to analysis of aerodynamic performance in horizontal-axis wind turbines (HAWTs)," Renewable and Sustainable Energy Reviews, vol. 63, pp. 506-519, 2016/09/01/2016.

[28] R. Lanzafame, S. Mauro, and M. Messina, "Evaluation of the Radial Flow Effects on Micro HAWTs through the Use of a Transition CFD 3D Model - part I: State of the Art and Numerical Model Review," Energy Procedia, vol. 82, pp. 156-163, 2015/12/01/ 2015.

[29] A. Rezaeiha, H. Montazeri, and B. Blocken, "On the accuracy of turbulence models for CFD simulations of vertical axis wind turbines," Energy, 2019/05/16/ 2019.

[30] J. M. O'Brien, T. M. Young, D. C. O'Mahoney, and P. C. Griffin, "Horizontal axis wind turbine research: A review of commercial CFD, FE codes and experimental practices," Progress in Aerospace Sciences, vol. 92, pp. 1-24, 2017/07/01/ 2017.

[31] W. Miao, C. Li, G. Pavesi, J. Yang, and X. Xie, "Investigation of wake characteristics of a yawed HAWT and its impacts on the inline downstream wind turbine using unsteady CFD," Journal of Wind Engineering and Industrial Aerodynamics, vol. 168, pp. 60-71, 2017/09/01/ 2017.

[32] F. Carneiro, L. Moura, P. C. Rocha, R. P. Lima, and K. Ismail, "Application and analysis of the moving mesh algorithm AMI in a small scale HAWT: Validation with field test's results against the frozen rotor approach," Energy, vol. 171, pp. 819-829, 2019.

[33] Y.-J. Chen, G.-Y. Huang, Y.-C. Shiah, and Y.-L. Tsai, "Performance Prediction for Small Horizontal Axis Wind Turbine (HAWT) by Integrated Theory and Experimental Verifications," International Journal of Precision Engineering and Manufacturing-Green Technology, pp. 1-10, 2019.
[34] S. Sakaria, M. Tailor, and S. Joshi, "Modeling \& Simulation Analysis of $800 \mathrm{~kW}$ Hawt," in ICTEA: International Conference on Thermal Engineering, 2019.

[35] F. R. Menter, M. Kuntz, and R. Langtry, "Ten years of industrial experience with the SST turbulence model," Turbulence, heat and mass transfer, vol. 4, pp. 625-632, 2003. 